\title{
Cathodo- and Photo- Luminescence of Silicon Rich Oxide Films Obtained by LPCVD
}

\author{
Rosa López-Estopier1, 2, Mariano Aceves-Mijares ${ }^{3}$ and Ciro Falcony ${ }^{4}$ \\ ${ }^{1}$ Department of Electronics, ITSPR, Poza Rica, Veracruz \\ 2Department of Applied Physics, ICMUV, University of Valencia, Burjassot, Valencia \\ ${ }^{3}$ Department of Electronics, INAOE, Tonantzintla, Puebla \\ ${ }^{4}$ Department of Physics, CINVESTAV-IPN, Distrito Federal \\ 1,3,4 México \\ 2Spain
}

\section{Introduction}

Silicon technology dominates the electronics industry today, so it is highly desirable the development of silicon-based components compatible with silicon technology, allowing integration of electrical and optical components on a single chip. One promising approach to the development of a silicon based light emitter is Silicon Rich Oxide (SRO), also called offstoichiometric silicon oxide. The interest on the optical properties of this material has grown since it was demonstrated that SRO films subjected to high-temperature annealing exhibit efficient photoluminescence (PL) (Iacona et al., 2000; Shimizu-Iwayama et al., 1996).

At present, different techniques have been employed to produce SRO films, these include plasma enhanced chemical vapor deposition (PECVD) (Pai et al., 1986), low pressure chemical vapor deposition (LPCVD) (Dong et al., 1978), silicon implantation into thermal oxide (SITO) (Pavesi et al., 2000), reactive sputtering (Hanaizumi et al., 2003) and others. An indicator of the $\mathrm{Si}$ content in this material is the parameter $\mathrm{R}_{0}$, which is the ratio of the partial pressure of the precursor gases (in this case, $\mathrm{N}_{2} \mathrm{O} / \mathrm{SiH}_{4}$ ) when it is prepared by gas phase deposition methods like CVD (Chemical Vapor Deposition). Silicon excess ranging from $17 \%$ to $0 \%$ can be obtained varying the $R_{0}$ from 3 to 100 . Among CVD methods, the low pressure chemical vapor deposition (LPCVD) is a very convenient approach for the deposition of SRO films since it allows an exact variation of the Si content and produces higher PL than other methods.

Different applications of SRO have been proposed, such as: visible light emission devices (Shimizu-Iwayama et al., 1996), non-volatile or electrically alterable memory devices (Calleja et al., 1998), surge suppressors (Aceves et al., 1999), microsensors (Aceves et al., 2001), and single electron devices (Yu et al., 2003).

SRO can be considered as a multi-phase material composed of a mixture of stoichiometric silicon oxide $\left(\mathrm{SiO}_{2}\right)$, off-stoichiometric oxide $\left(\mathrm{SiO}_{x}, \mathrm{x}<2\right)$ and elemental silicon. After thermal treatment at temperatures above $1000^{\circ} \mathrm{C}$, off-stoichiometric oxide and silicon excess are separated into $\mathrm{Si}$ nanoClusters (crystalline or amorphous depending on their size), defects (oxidation states) and $\mathrm{SiO}_{2}$ (Yu et al., 2006b). Transmission electron microscopy (TEM) studies 
on the PECVD-SRO films with $\mathrm{Si}$ excess of $4-9 \%$ have confirmed the existence of $\mathrm{Si}$ nanocrystals with sizes between 1-2 nm (Iacona et al., 2000). The observation of Si nanocrystals in LPCVD-SRO films with Si excess of $\sim 13 \%$ has also been reported (Irene et al., 1980). Although no Si nanocrystals were observed in LPCVD-SRO with less Si excess (<6\%) (DiMaria et al., 1984), however, it was still proposed that amorphous $\mathrm{Si}$ nanodots exist in the $\mathrm{SiO}_{2}$ matrix, which could not be distinguished by TEM (Nesbit, 1985). It was found that the growth of the $\mathrm{Si}$ nanodots is a diffusion-controlled process with a diffusion coefficient as larger as $1 \times 10^{-16} \mathrm{~cm}^{2} / \mathrm{s}$ at $1100^{\circ} \mathrm{C}$ (Nesbit, 1985); it is estimated that a diffusion length of $10-20 \mathrm{~nm}$ can be obtained during the thermal annealing of 3 hours. This diffusion length is long enough for the excess $\mathrm{Si}$ to precipitate into $\mathrm{Si}$ nanodots during the annealing process.

Depending of the silicon excess, SRO shows various properties, among others, variable conductivity (Aceves et al., 1999), charge-trapping effect (Aceves, et al., 1996) and photoluminescence (PL) (Shimizu-Iwayama et al., 1996). These properties depend on the concentration and the exact nature of the excess Si. For example, the trapped charge density and photoluminescence intensity of SRO increase with decreasing its Si excess. The light emission is one promising property of SRO that makes it a good candidate for future's lightemitting devices. It has been observed that strong visible light can be emitted from SRO films deposited by LPCVD, its emission wavelength and intensity is tuned by the Si excess and thermal annealing parameters (temperature and time). It has also been found that SRO can trap both negative and positive charges, and the trapped charge density depends on the same parameters.

Although this material has been extensively studied there is a considerable uncertainty about the nature of the luminescence mechanisms. A clear understanding of the luminescence mechanisms in SRO is the key for the production of silicon-based lightemitting devices. Some authors attribute the luminescence to quantum confinement effects (QCE) in Si-nCs (Si nanocrystals) (Chen et al., 2006; Iacona et al., 2000), to the emission of several types of defects in the matrix or in the interface of $\mathrm{SiO}_{2} / \mathrm{Si}$-nCs (Kenyon et al.1996; Lockwood et al., 1996), including the decay of donor acceptor pairs, DAD (López-Estopier et al., 2011; Yu et al., 2006a).

Even though SRO has been strongly study by PL, there are only a few works that study the cathodoluminescence (CL) of SRO. CL expands the possibilities to understand the emission in SRO. For example point defects in silicon oxide and silicon could be observed trough CL, allowing studying the distribution of such defects on the surface and inside the structure. An advantage of this method is the possibility to observe optical transitions of electrons from high energy levels (or band to band), which need to be exited with high energies, this is very important for wide-gap materials.

CL and PL are similar techniques with some possible differences associated with the excitation of the electron-hole pairs due to photons or more energetic electrons (Yacobi \& Holt, 1990). PL emission depends strongly on the excitation energy, and not all luminescence mechanism could be excited. Cathodoluminescence, in general, leads to emission by all the luminescence mechanism present in the solid due to the high energy excitation.

In this chapter, different techniques, such as Fourier transform infrared spectroscopy (FTIR), $\mathrm{X}$-ray photoelectron spectroscopy (XPS), photoluminescence (PL) and cathodoluminescence 
(CL) were used to study SRO films obtained by LPCVD. In section 2, the experimental details of the fabrication of SRO films and their characterization techniques used are described. Section 3 gives the results of the structural and optical measurements. Also, in this section, the discussion and analysis of the results are included. Finally, in Section 4, conclusions are drawn. The structural and optical properties of SRO-LPCVD films were related to better understand the process of light emission in these materials.

\section{Experimental}

SRO samples were deposited by Low Pressure Chemical Vapor Deposition (LPCVD) at 720 ${ }^{\circ} \mathrm{C}$ on n-type $\mathrm{Si}$ substrates. The silicon excess in the SRO films was varied by adjusting the ratio of partial pressure of the reactive gases, Silane $\left(\mathrm{SiH}_{4}\right)$ and Nitrous Oxide $\left(\mathrm{N}_{2} \mathrm{O}\right)$.

$$
R_{0}=\frac{P_{\left[\mathrm{N}_{2} \mathrm{O}\right]}}{P_{\left[\mathrm{SiH}_{4}\right]}}=10,20 \text { and } 30
$$

With this $\mathrm{R}_{0}$ variation a silicon excess of $11-5.5 \%$ is approximately obtained. The SRO layers thickness is about $300 \mathrm{~nm}$. After the deposition, one part of samples was keep as deposited and other part was annealed at $1100^{\circ} \mathrm{C}$ in $\mathrm{N}_{2}$ atmosphere during 180 minutes.

The PL emission spectra were obtained with a Fluoromax-3 Spectrofluorometer; all the films were excited with $250 \mathrm{~nm}$. Cathodoluminescence (CL) measurements were performed using a Luminoscope equipment model ELM2-144, $0.3 \mathrm{~mA}$ current and energies of 2.5, 5, 10 and $15 \mathrm{keV}$ were used. The luminescence spectra (PL and CL) were measured at the room temperature. The IR spectra were measured with a Brucker FTIR spectrometer model V22, which works in a range of 4000-350 $\mathrm{cm}^{-1}$ with $5 \mathrm{~cm}^{-1}$ resolution. The silicon excess in SRO films was measured with a PHI ESCA-5500 X-ray photoelectron spectrometer (XPS) using a monochromatic $\mathrm{Al}$ radiation source with energy of $1486 \mathrm{eV}$.

\section{Results and discussion}

\subsection{Compositional and structural properties}

The IR absorbance spectra of SRO samples are depicted in Fig. 1. Their characteristic absorption bands are enumerated and identified in the Table 1. SRO films show the absorption peaks associated with rocking at $\sim 458 \mathrm{~cm}^{-1}$, bending at $\sim 812 \mathrm{~cm}^{-1}$ and stretching at $\sim 1080 \mathrm{~cm}^{-1}$ vibration modes of the Si-O-Si bonds in $\mathrm{SiO}_{2}$ (Ay \& Aydinli, 2004; Pai et al., 1986). In addition, the shoulder at $\sim 1150 \mathrm{~cm}^{-1}$ corresponds to the out-of-phase Si-O stretching vibration (Pai et al., 1986). The insets of Fig. 1 show Si-N stretching vibration at $\sim 886-990 \mathrm{~cm}^{-1}$ (Ay \& Aydinli, 2004; Daldosso et al., 2007); in addition Si-H bending and stretching at $\sim 886$ and $2258 \mathrm{~cm}^{-1}$ respectively (Iacona et al., 2000).

The as deposited samples exhibit a characteristic IR absorption at a lower frequency than that of a thermal $\mathrm{SiO}_{2}$ film $\left(1080 \mathrm{~cm}^{-1}\right)$, and the frequency of stretching vibration peak decreases as $\mathrm{R}_{0}$ decreases due to $\mathrm{Si}$ atoms replacing $\mathrm{O}$ atoms (Pai et al., 1986); this result is related to offstoichiometric of $\mathrm{SRO}$, frequency of the $\mathrm{Si}-\mathrm{O}$ stretching decreases with $\mathrm{x}$ of $\mathrm{SiO}_{\mathrm{x}}$ (silicon excess increases). For all samples, the stretching frequency increases after annealing for all silicon excess, this result suggest phase separation during the thermal annealing. 


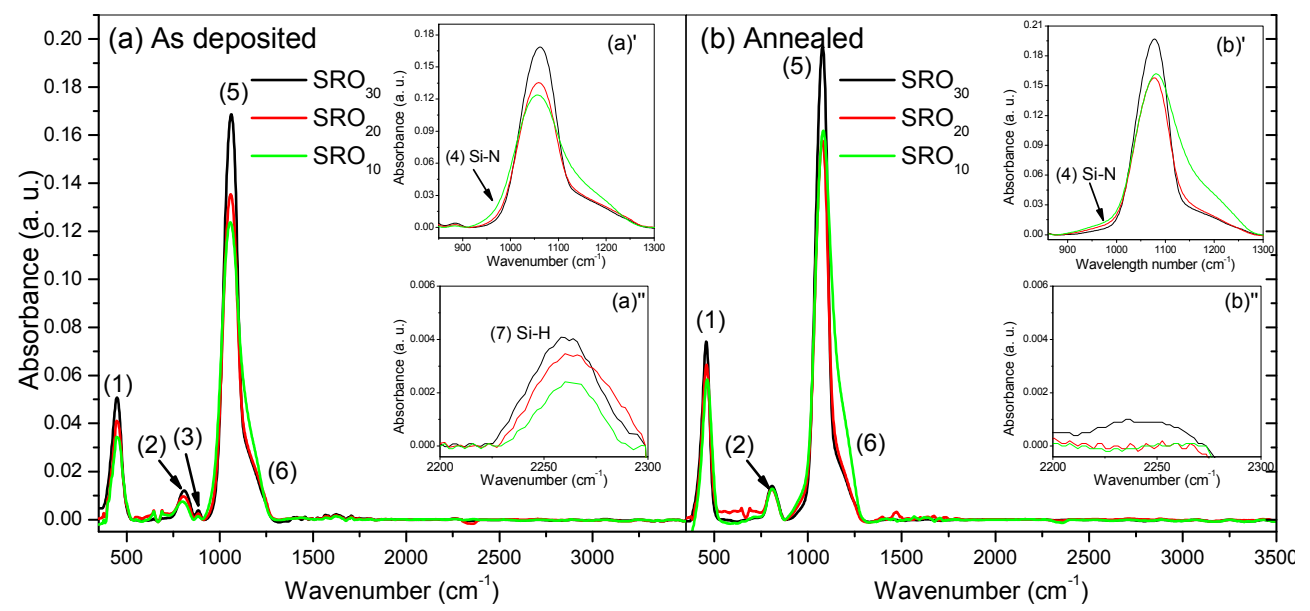

Fig. 1. FTIR absorption spectra of SRO films with $\mathrm{R}_{0}=10$ (a) before and (b) after thermal annealing. The inset shows Si-N and Si-H bonding in the 850 to $1300 \mathrm{~cm}^{-1}$ and 2200 to 2300 $\mathrm{cm}^{-1}$ range.

\begin{tabular}{|c|c|c|c|c|c|c|}
\hline \multirow{3}{*}{ Vibration mode } & \multicolumn{6}{|c|}{ Wavenumber $\left[\mathrm{cm}^{-1}\right]$} \\
\hline & \multicolumn{3}{|c|}{ As deposited } & \multicolumn{3}{|c|}{ Annealed } \\
\hline & $\mathrm{SRO}_{30}$ & $\mathrm{SRO}_{20}$ & $\mathrm{SRO}_{10}$ & $\mathrm{SRO}_{30}$ & $\mathrm{SRO}_{20}$ & $\mathrm{SRO}_{10}$ \\
\hline (1) Si-O rocking & 447 & 445 & 455 & 457 & 459 & 460 \\
\hline (2) Si-O bending & 810 & 808 & 802 & 808 & 808 & 810 \\
\hline (3) Si-H bending & 883 & 883 & 883 & - & - & - \\
\hline (4) Si-N stretching & 980 & 984 & 940 & 984 & 991 & 954 \\
\hline (5) Si-O symmetric stretching & 1060 & 1058 & 1055 & 1078 & 1078 & 1082 \\
\hline (6) Si-O asymmetric stretching & 1176 & 1170 & 1159 & 1192 & 1190 & 1190 \\
\hline (7) Si-H stretching & 2258 & 2258 & 2258 & - & - & - \\
\hline
\end{tabular}

Table 1. Infrared vibrations modes observed in the as deposited samples.

It has been reported that SRO films deposited by the mixture of $\mathrm{N}_{2} \mathrm{O}$ and $\mathrm{SiH}_{4}$ display absorption bands associated with Si-H $\left(660,880,2250 \mathrm{~cm}^{-1}\right)$, Si-N $\left(870-1030 \mathrm{~cm}^{-1}\right)$, Si-OH (940, $\left.3660 \mathrm{~cm}^{-1}\right)$ and $\mathrm{N}-\mathrm{H}\left(1150,1180,3380 \mathrm{~cm}^{-1}\right)$ vibrations in addition to the three characteristic bands related to the Si-O-Si bonding arrangement (Fazio et al., 2005; Pai et al., 1986). The presence of some nitrogen and hydrogen characteristic peaks was also observed in the IR spectra of the films. Si-H bending and stretching were observed only in as deposited samples; these peaks disappear after annealing. Si-N stretching was also found in as deposited and annealing samples. 

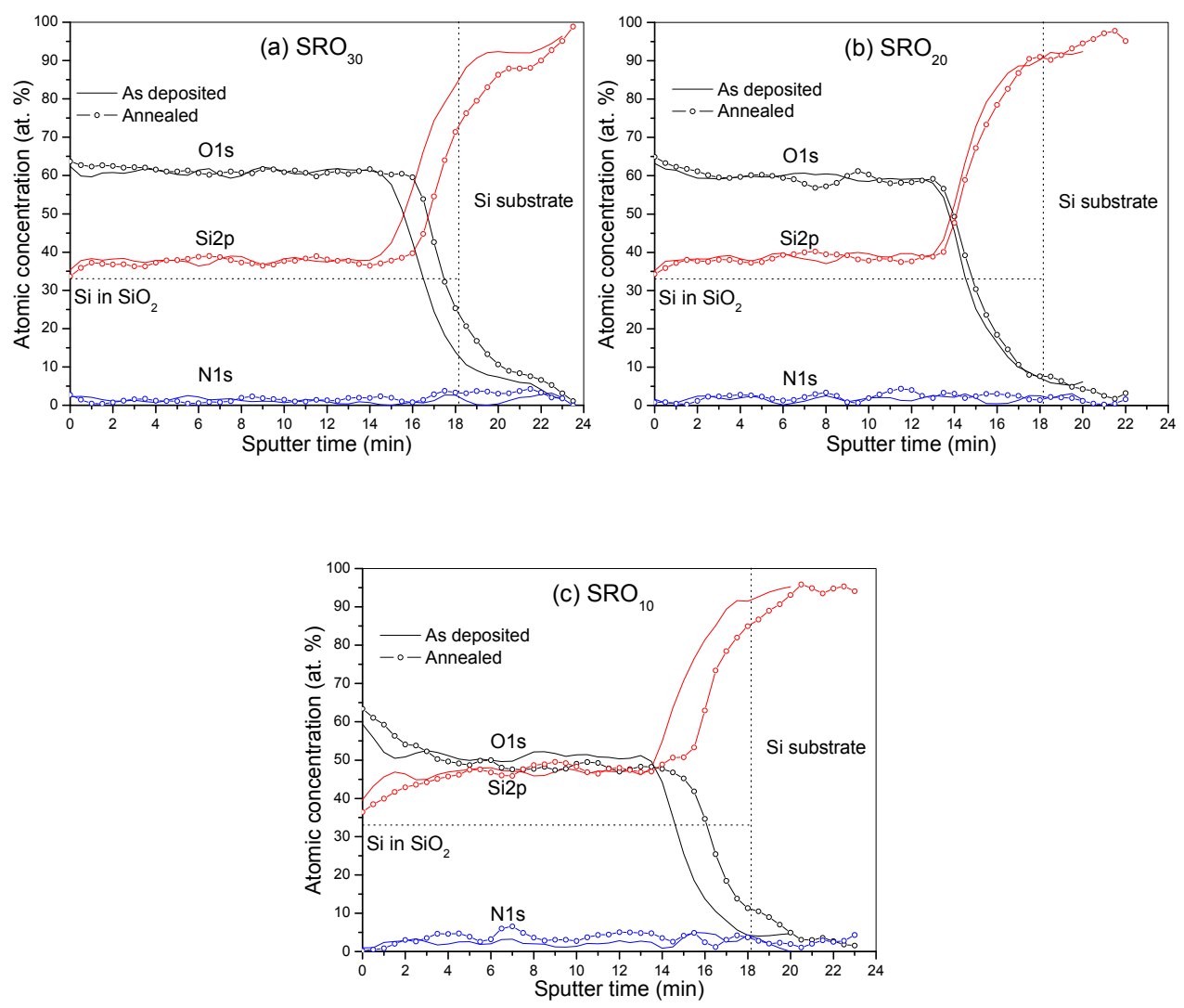

Fig. 2. Silicon, oxygen and nitrogen concentration in SRO films with different flow ratio $\left(\mathrm{R}_{0}\right)$ values as measured by XPS.

Fig. 2 indicates the composition measured by XPS of as deposited and annealed SRO films with different flow ratio, $\mathrm{R}_{0}=30,20$ and 10. As it was expected, the silicon excess varies depending on the flow ratio $\left(\mathrm{R}_{0}\right)$. For $\mathrm{SRO}$ films with $\mathrm{R}_{0}=30$, the silicon profile stays about 37.5 at. $\%$ and it increases until 47 at. $\%$ as $R_{0}$ value reduces to 10 . A thin silicon dioxide layer is formed at the SRO surface; which can be explained by the silicon oxidation at the end of the deposition process. A nitrogen profile was also observed, however is negligible, specially compared with that reported for SRO-PECVD films where the $\mathrm{N}$ incorporation is about 10 at.\% (Morales et al., 2007; Ribeiro et al., 2003). Table 2 summarizes the silicon excess in the SRO films; silicon $(\mathrm{Si})$, oxygen $(\mathrm{O})$ and nitrogen $(\mathrm{N})$ concentration in SRO is also shown. 


\begin{tabular}{|c|c|c|c|c|c|c|c|c|c|c|}
\hline \multirow{3}{*}{$\mathbf{R}_{\mathbf{0}}$} & \multicolumn{5}{|c|}{ As deposited } & \multicolumn{5}{|c|}{ Annealed } \\
\hline & \multirow{2}{*}{$\begin{array}{c}\text { Si excess } \\
\text { (at. \%) }\end{array}$} & \multicolumn{3}{|c|}{ Concentration (\%) } & \multirow{2}{*}{$\begin{array}{c}\mathrm{SiOx} \\
\mathrm{x}=\mathrm{O} / \mathrm{Si}\end{array}$} & \multirow{2}{*}{$\begin{array}{c}\text { Si excess } \\
(\text { at. } \%)\end{array}$} & \multicolumn{3}{|c|}{ Concentration (\%) } & \multirow{2}{*}{$\begin{array}{c}\text { SiOx } \\
x=\mathrm{O} / \mathrm{Si}\end{array}$} \\
\hline & & $\mathrm{O}$ & Si & $\mathbf{N}$ & & & $\mathrm{O}$ & Si & $\mathbf{N}$ & \\
\hline 30 & 4.54 & 60.90 & 37.87 & 1.23 & 1.61 & 4.21 & 61.15 & 37.54 & 1.31 & 1.63 \\
\hline 20 & 5.38 & 59.67 & 38.71 & 1.62 & 1.54 & 5.09 & 59.29 & 38.42 & 2.29 & 1.54 \\
\hline 10 & 13.50 & 50.89 & 46.83 & 2.28 & 1.09 & 14.50 & 48.09 & 47.83 & 4.07 & 1.01 \\
\hline
\end{tabular}

Table 2. Silicon excess and atomic concentration of SRO films obtained by XPS.

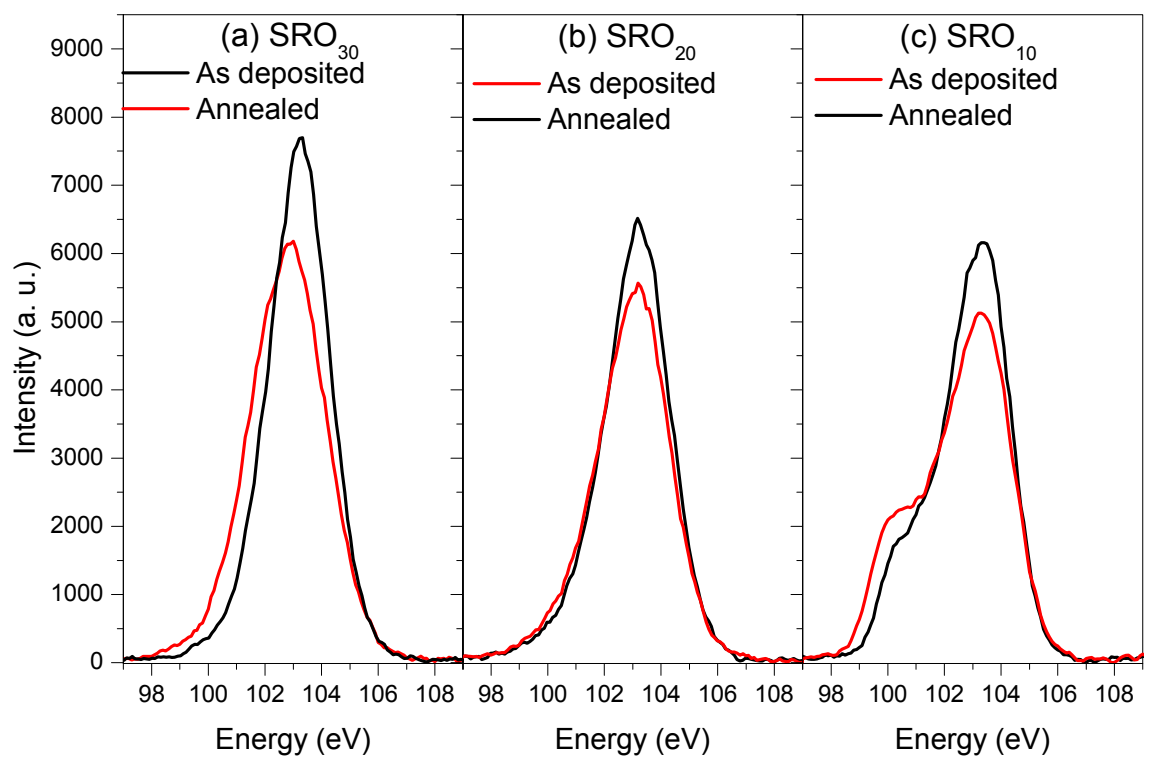

Fig. 3. Si $2 \mathrm{p}$ XPS peaks for as deposited and annealed samples with different flow ratio $\left(\mathrm{R}_{0}\right.$ 30,20 and 10).

The microstructure of SRO films was studied based on the analysis of the Si $2 p$ spectra, shown in Fig. 3. As can be seen, the effect of silicon excess and thermal treatment is evident. After annealing and as silicon increases the shoulder in low energies becomes apparent, indicating the contribution of different oxidation states according to the random bonding model (RBM) (Chen et al., 2004, 2005).

The Si 2p XPS peaks were deconvoluted considering the five possible oxidation states for the silicon: $\mathrm{Si}, \mathrm{Si}_{2} \mathrm{O}, \mathrm{SiO}, \mathrm{Si}_{2} \mathrm{O}_{3}$, and $\mathrm{SiO}_{2}$, noted as $\mathrm{Si}^{+0}, \mathrm{Si}^{+1}, \mathrm{Si}^{+2}, \mathrm{Si}^{+3}$ and $\mathrm{Si}^{+4}$ respectively, shown in Fig. 4. Each oxidation state has been fitted by using peaks constituted by Gaussians. The energy positions of the different peaks of the Gaussians were centered with those previously reported in the literature at $\sim 99.8,100.5,101.5,102.5$ y $103.5 \mathrm{eV}$ (Alfonsetti et al., 1993; Brüesch et al., 1993; Philipp, 1972; Wang et al., 2003; Yang et al., 2005). The full widths at half maximum (FWHM) have been allowed to vary within a small range of values while increasing in the order $\mathrm{Si}^{0+}<\mathrm{Si}^{1+}<\mathrm{Si}^{2+}<\mathrm{Si}^{3+}<\mathrm{Si}^{4+}$ (Dehan et al., 1995; Liu et al., 2003). $\mathrm{Si}^{0+}$ compounds were found in all samples in both before and after annealing due to silicon excess. 


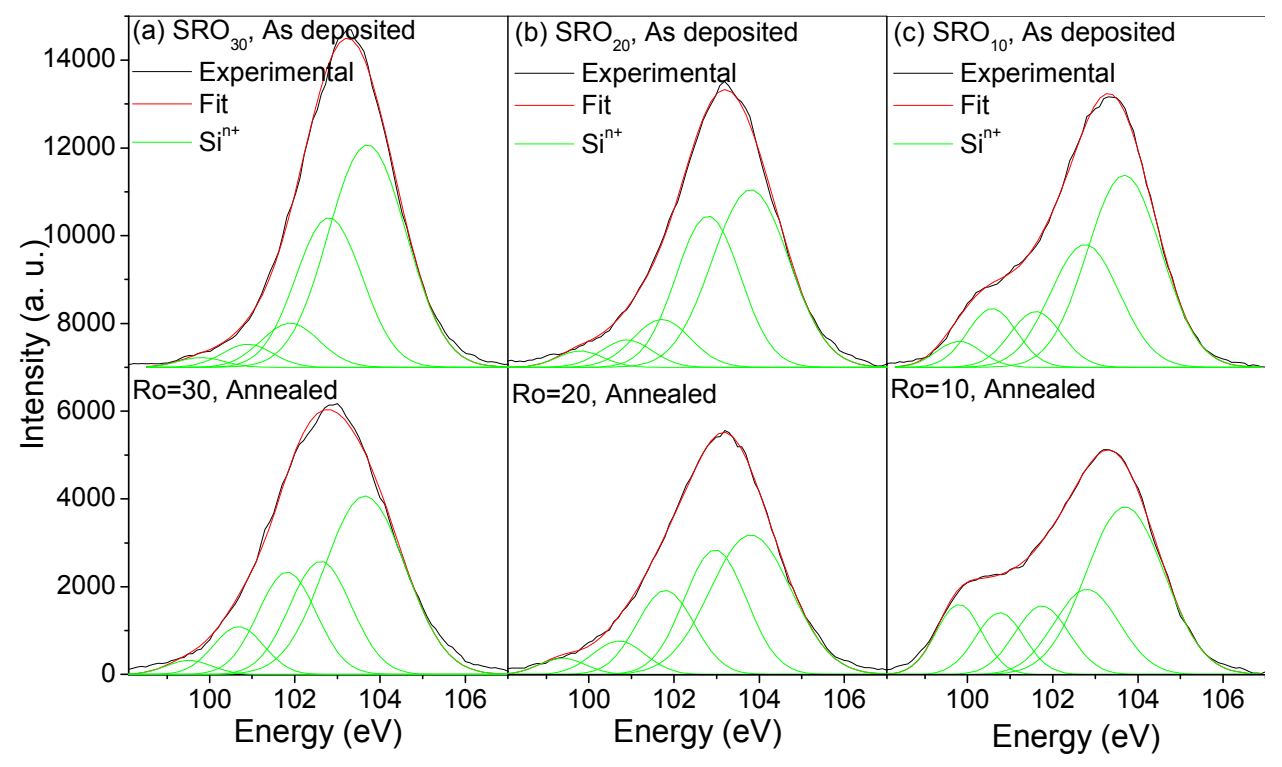

Fig. 4. Illustration of Si 2p peak deconvolution for the SRO films with $\mathrm{R}_{0}$ : (a) 30, (b) 20 and (c) 10 .

It would be useful to examine quantitatively the changes of the concentrations of the five oxidation states with annealing. In this regard, as a first-order approximation, the relative concentration (in percentage) of each oxidation state is obtained by calculating the ratio $I_{S i}^{n+} / I_{\text {Total }}\left(\mathrm{n}=0,1,2,3\right.$, and 4), where $I_{S i}^{n+}$ is the peak area of the oxidation state $\mathrm{Si}^{{ }^{+}+}$and $I_{\text {total }}$ is the total area of the Si 2 p peaks $\left(I_{\text {total }}=\sum_{i=0}^{4} I_{S i^{i+}}\right.$ ) (Khriachtchev et al., 2002; Liu et al., 2003).

Fig. 5 shows the effect of annealing in the concentrations of the five oxidation states for $\mathrm{R}_{0}$ 30, 20 and 10. After annealing concentration of $\mathrm{Si}^{0+}, \mathrm{Si}^{1+}, \mathrm{Si}^{2+}$ increases while $\mathrm{Si}^{3+}$ and $\mathrm{Si}^{4+}$ compounds decrease in all silicon excess indicating the phase separation; this separation is more evident in $\mathrm{R}_{0} 10$. Then, when SRO films are thermally annealed and the silicon excess is high, the silicon atoms diffuse around of a nucleation site and well defined silicon nanocrystals are observed. However, for lower excess silicon films, the particles are far enough and do not produced agglomeration, therefore the thermal diffusion causes the silicon to be redistributed and form compounds with oxygen. These two mechanisms are not mutually exclusive and both exist simultaneously, but depending on the silicon excess will dominate a mechanism or the other. Because of this effect, concentration of $\mathrm{Si}^{0+}$ is much higher in $\mathrm{SRO}_{10}$ than $\mathrm{SRO}_{20}$ and $\mathrm{SRO}_{30}$; in addition the concentration of $\mathrm{Si}^{1+} \mathrm{y} \mathrm{Si}^{2+}$ is larger for films with low silicon excess $\left(\mathrm{SRO}_{20}\right.$ and $\left.\mathrm{SRO}_{30}\right)$.

On the other hand, it is well known that in SRO with a large excess silicon (higher than $10 \%$ ), Si-nCs of $\sim 9 \mathrm{~nm}$ have been found by TEM (Transmission Electron Microscopy), as the silicon excess decreases, the density and size of the nanocrystals decreases until there are no Si-nCs ( 5.5\% silicon excess) (Yu et al., 2006b). Since the presence of $\mathrm{Si}^{0+}$ compounds in 
$\mathrm{SRO}_{20,30}$, agglomeration of amorphous compounds is more likely than elemental silicon agglomeration (nCs), and its possible size is smaller than $2 \mathrm{~nm}$, then they cannot be observed by TEM.

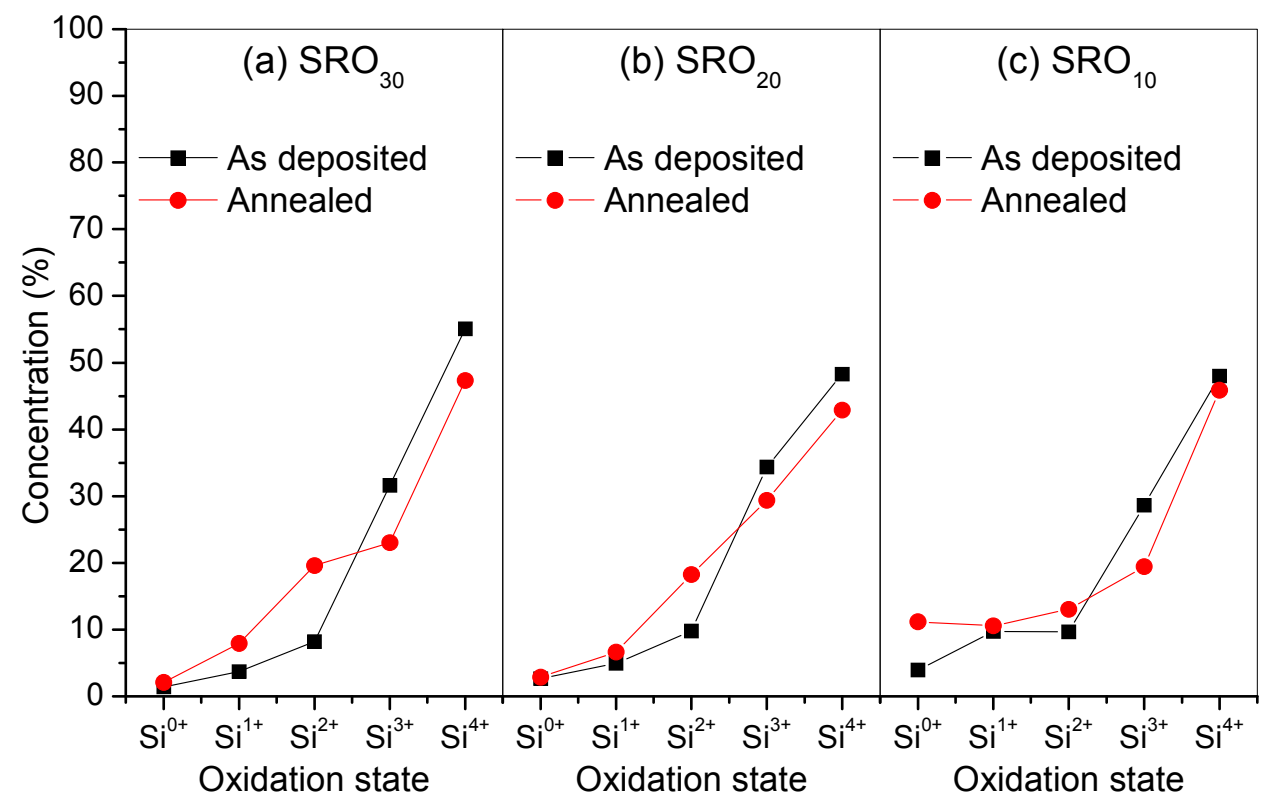

Fig. 5. Changes in the concentration of the five $\mathrm{Si}$ oxidation states $\operatorname{Sin}^{\mathrm{n}+}(\mathrm{n}=0,1,2,3$, and 4$)$ for different $\mathrm{R}_{0}$ values.

\subsection{Photoluminescence}

PL spectra of as deposited and annealed films are depicted in Fig. 6. The as deposited samples present a weak emission only in $\mathrm{SRO}_{30}$ from $\sim 460$ to $650 \mathrm{~nm}$. After annealing all SRO films $\left(R_{0}=10,20\right.$ and 30) present a main emission from $\sim 650$ to $850 \mathrm{~nm}$. This emission range is characteristic of SRO annealed films deposited by LPCVD (López-Estopier et al., 2011; Yu et al., 2006a).The emission intensity increases when the silicon excess decrease.

The multi-Gaussian deconvolution of PL spectra was performed only for annealed samples, and the set of band positions have been determined. As can be seen in Fig. 7, each spectrum can be well fitted to a superposition of three Gaussian distributions: a main band and two shoulders. Fit distributions are centered at 715, 780, $825 \mathrm{~nm}$ with FWHM of 101, 80, $47 \mathrm{~nm}$ respectively. Distribution position and FWHM are the same for all $\mathrm{R}_{0}$ values while intensity varies according to the silicon excess. As silicon excess decreases the intensity of main distribution increase; however, distributions centered at 780 and $825 \mathrm{~nm}$ are more intense to $\mathrm{SRO}_{20}$ than $\mathrm{SRO}_{30}$; because of this $\mathrm{PL}$ emission of $\mathrm{SRO}_{20}$ shows a shoulder in this region. Distribution centered at $715 \mathrm{~nm}$ is the highest emission $\left(R_{0}=20\right.$ and 30$)$, hence this distribution is the main contribution of the PL emission. Since there are different distributions that change with silicon excess can be assumed that PL emission is related with at least three different types of emission centers (or emission mechanism). 


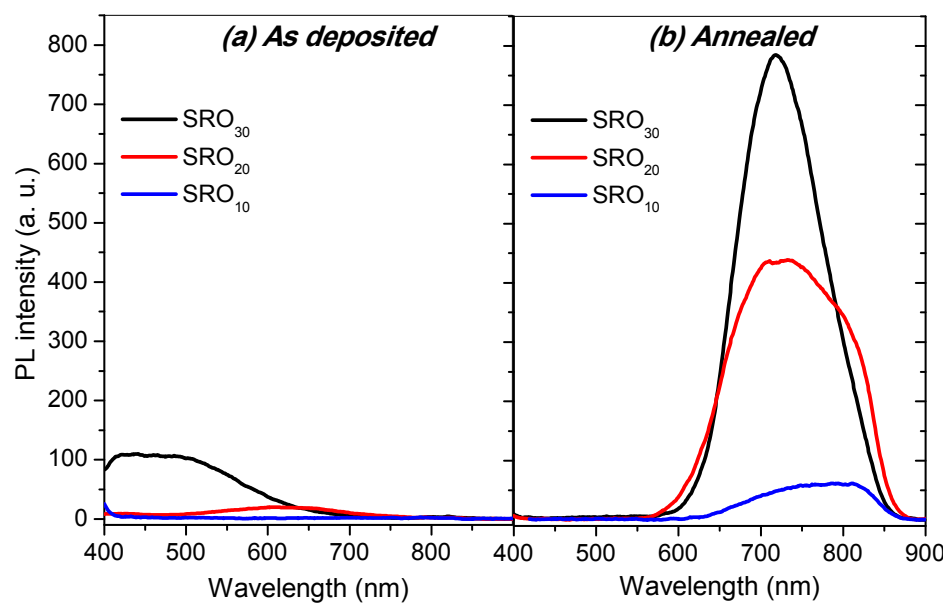

Fig. 6. Photoluminescence of (a) as deposited and (b) annealed SRO films with different ratio flows.

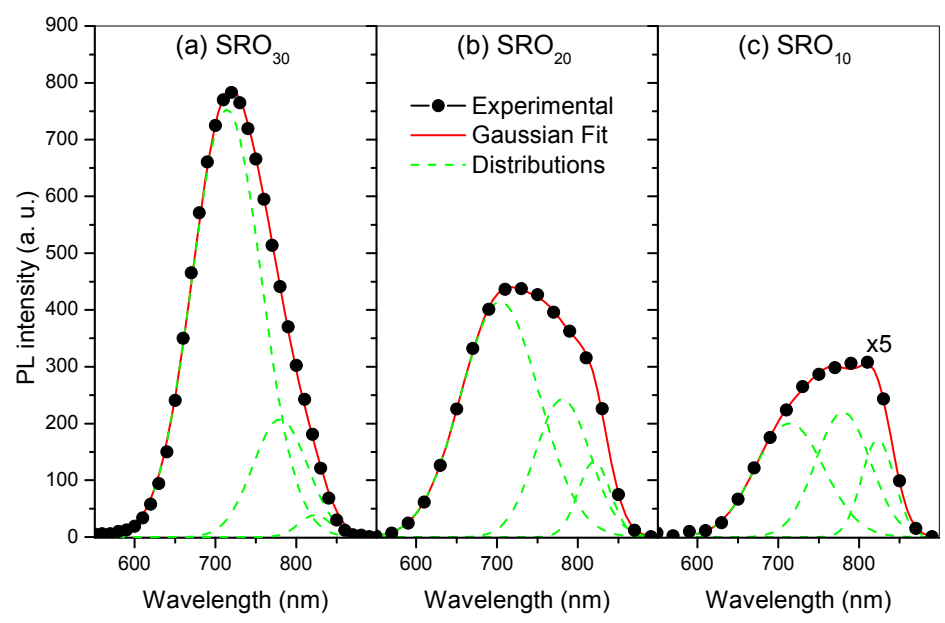

Fig. 7. PL spectra and fits from SRO films with different silicon excess and annealed at $1100^{\circ}$ $\mathrm{C}$ for $180 \mathrm{~min}$. Symbols are experimental data, lines are the Gaussian fits and dash lines are distributions.

\subsection{Cathodoluminescence}

CL spectra from SRO films (as deposited and annealed) with different silicon excess are depicted in Fig. 8. In as deposited samples there is $\mathrm{CL}$ emission only in $\mathrm{SRO}_{30}$. The CL spectra of SRO with thermal treatment consist of a broad emission in the visible and near infrared region (NIR) from $\sim 400$ to $850 \mathrm{~nm}$. After annealing, intensity of the blue band at $\sim 460 \mathrm{~nm}$ increases with increasing the $\mathrm{R}_{0}$. On the other hand, the intensity of the red-NIR CL band seems to have a maximum for $\mathrm{R}_{0}=20$. 


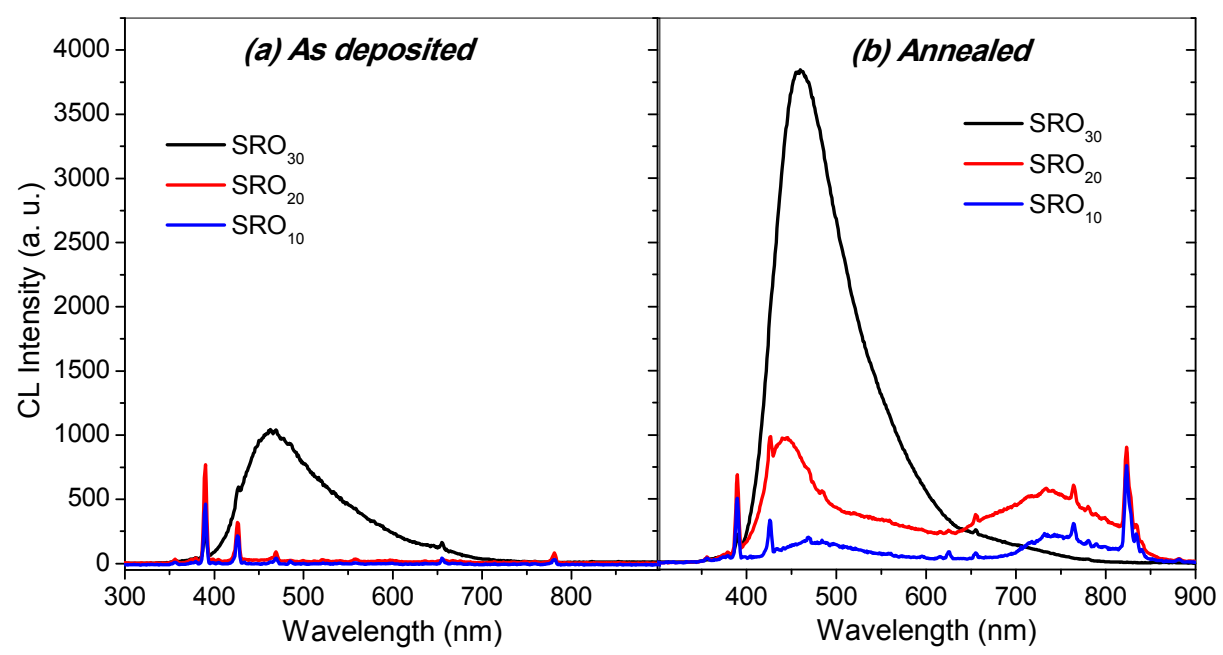

Fig. 8. Cathodoluminescence spectra from SRO films with different silicon excess: (a) as deposited and (b) annealed. Energy excitation of $5 \mathrm{keV}$ and $0.3 \mathrm{~mA}$ current was used.

Since CL emission has asymmetrical shape for all SRO samples, it can be assumed that CL emission is due to different causes. Hence, multi-Gaussian deconvolution of CL spectra was also obtained, shown in Fig. 9. The best fit of CL spectra requires 4 and 6 distributions for $\mathrm{SRO}_{30}$ and $\mathrm{SRO}_{20}$ respectively. Distributions were obtained at about 460, 522, 643, and $714 \mathrm{~nm}$ for $\mathrm{SRO}_{30}$ and 447, 541, 645, 714, 780 and $823 \mathrm{~nm}$ for $\mathrm{SRO}_{20}$. Distributions obtained at 714, 780 and $823 \mathrm{~nm}$ in CL are centered in the same position than distributions obtained from PL spectrum in $\mathrm{SRO}_{20}$. Furthermore, distribution centered at $714 \mathrm{~nm}$ was obtained for Gaussian fit, in PL and CL in $\mathrm{SRO}_{30}$. Then, the red emission of the CL emission can be ascribed to the same PL emissive centers. PL distributions in higher wavelength are not observed in CL due to either destruction of the emissive centers or emissive center with lower energies do not efficiently emit (Trukhin et al., 1999). The latter one could rise because cathode excited electrons acquire so high energy that they arrive to the higher emissive center where they emit in the blue region (higher energy), however almost none of the excited electrons reach lower energy centers; then, the red emission is not likely to occur. Therefore, there could be several different kinds of emission centers located at different energy levels in SRO.

Depending on the emission wavelength, multiple luminescence centers have been reported to act as radiative recombination centers in $\mathrm{SiO}_{2}$ films. Luminescent emission at $460 \mathrm{~nm}(2.7 \mathrm{eV}), 520 \mathrm{~nm}(2.4 \mathrm{eV})$ and $650 \mathrm{~nm}(1.9 \mathrm{eV})$ are mainly related to defects such as Oxygen deficiency-related centers (ODC) or oxygen vacancies (Cervera et al., 2006; Fitting, 2009; Gritsenko et al., 1999), E' $\delta$ defect or peroxide radical (Goldberg et al., 1997) and non-bridging oxygen hole centers (NBOHC) (Fitting, 2009; Fitting et al., 2001; Gritsenko et al., 1999), respectively. Since CL measurements have shown luminescent peaks (or distributions) close to those wavelengths, such defects could be inside the SRO films. 


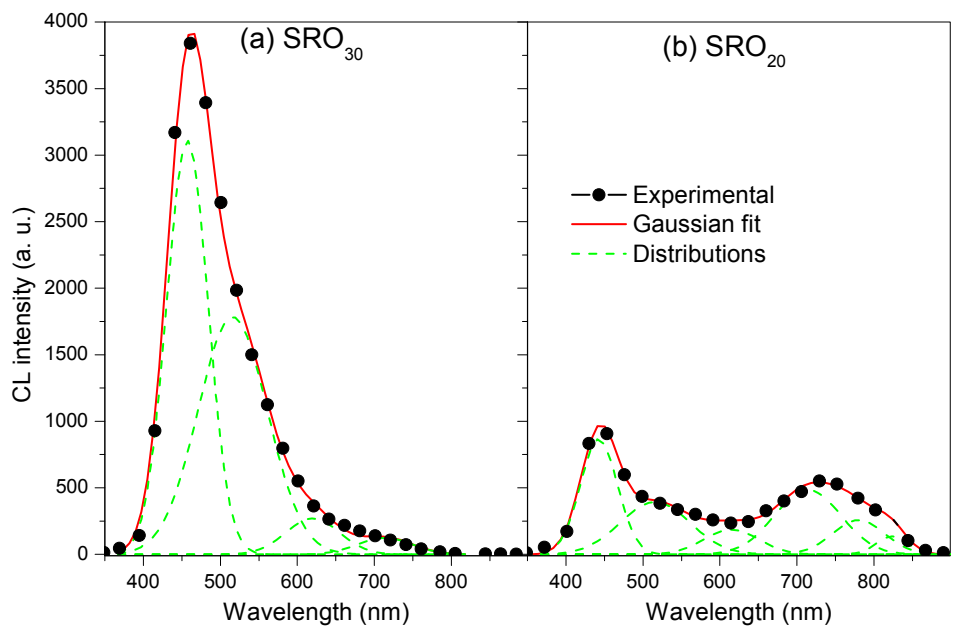

Fig. 9. Gaussian fit of CL experimental spectrum, the best fit requires 4 distributions for (a) $\mathrm{SRO}_{30}$ and 6 distributions for (b) $\mathrm{SRO}_{20}$. Symbols are experimental data, lines are the Gaussian fits and dash lines are distributions.
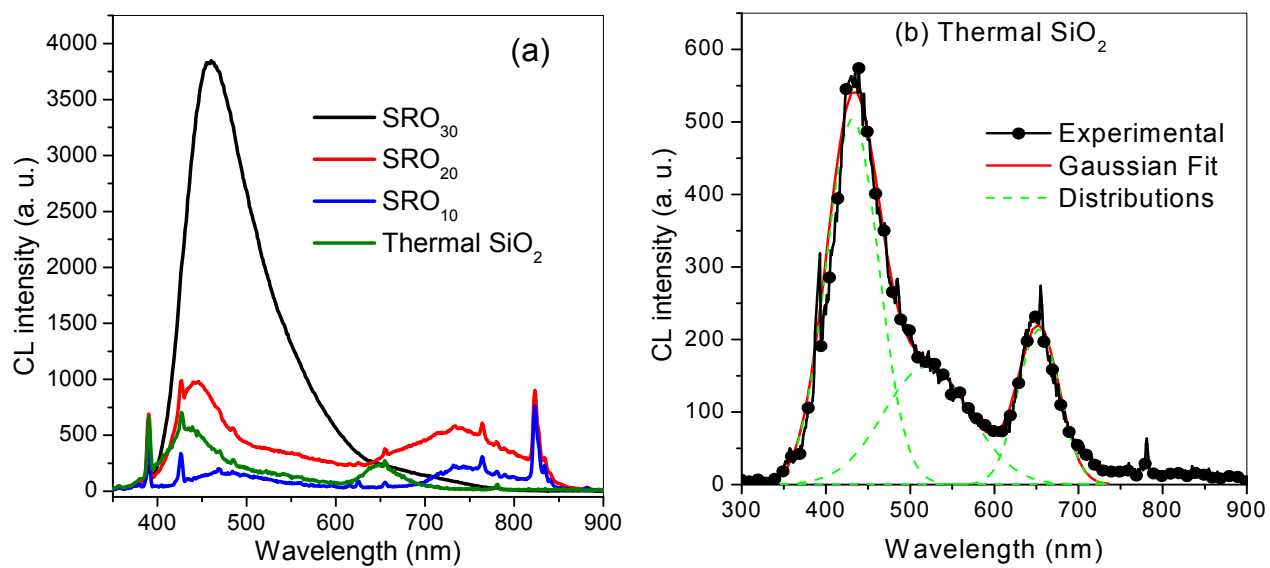

Fig. 10. (a) CL spectra of thermal $\mathrm{SiO}_{2}$ and $\mathrm{SRO}$ annealed samples and (b) Gaussian fit of thermal $\mathrm{SiO}_{2}$ sample.

In order to compare CL spectra between $\mathrm{SiO}_{2}$ and $\mathrm{SRO}, \mathrm{CL}$ spectrum from thermal $\mathrm{SiO}_{2}$ was obtained, as shown in Fig. 10 (a). CL of $\mathrm{SiO}_{2}$ results are helpful because a large fraction of the SRO films consists of silicon oxide. As can be seen, spectrum from thermal $\mathrm{SiO}_{2}$ is similar to $\mathrm{SRO}_{20}$ but it does not include the red to infrared emission. To compare emission bands, Gaussian deconvolution was also obtained from thermal oxide; the best fit was centered at 432, 520 and $653 \mathrm{~nm}$, as shown in Fig. 10 (b). Clearly only the $650 \mathrm{~nm}$ peak in both $\mathrm{SRO}_{20}$ and $\mathrm{SiO}_{2}$ are comparable. The other emissions are enhanced in both Ro 20 and 30. That could mean that emission in SRO with low silicon excess and without silicon nCs are mainly due to silicon oxidation states. 
In summary, luminescence peaks at 460,520 , and $620 \mathrm{~nm}$ are mainly due to defects such as Oxygen deficiency-related centers (ODC), E' $\delta$ defect, and non-bridging oxygen hole centers (NBOHC), respectively (Cervera et al., 2006; Fitting et al., 2001; Inokuma et al., 1998). Electroluminescence (EL) studies on SRO films with the same silicon excess as in this work exhibit an emission band similar to our CL results with peaks at 450,500, 550, and $640 \mathrm{~nm}$ (Morales-Sánchez et al., 2010).Then the mentioned defects should exist into the SRO films, which are only excited with electron of high energy generated by CL or by EL.

The emission in red and NIR region could be associated to Si-clusters of less of $2 \mathrm{~nm}$ and defects interaction. In (Morales-Sánchez et al., 2008), the authors proposed that the band gap is large when the size of the Si cluster is small, and then the energy difference between the defects (localized state) and the Si clusters is big enough to produce the emission. This result is similar to the decay of Acceptor-Donator pair in a crystalline semiconductor. Therefore, we can assume that the absorption and emission processes in SRO films are connected with electrons decay between donor acceptor pairs (localized states) inside the silicon oxide band gap.

\subsection{Depth profiling by different electron beam energy}

It is well known that depth analysis can be obtained varying the electron energy (excitation range of CL) (Goldberg et al., 1998; Wittry \& Kyser, 1967). In this case the CL intensity versus energy would remain constant when assuming a homogeneous depth distribution of luminescence centers. Deviation of such a behavior is easy to detect and should be interpreted.

The depth-resolved CL spectra for SRO annealed samples measured with electron beam energies of 2.5, 5, 10 and $15 \mathrm{keV}$ was obtained, shown in Fig. 11. As can be seen, there is no band shift or any new emission bands by varying the beam energy, indicating specific luminescence correlated with a homogeneous depth impurity distribution in the samples.

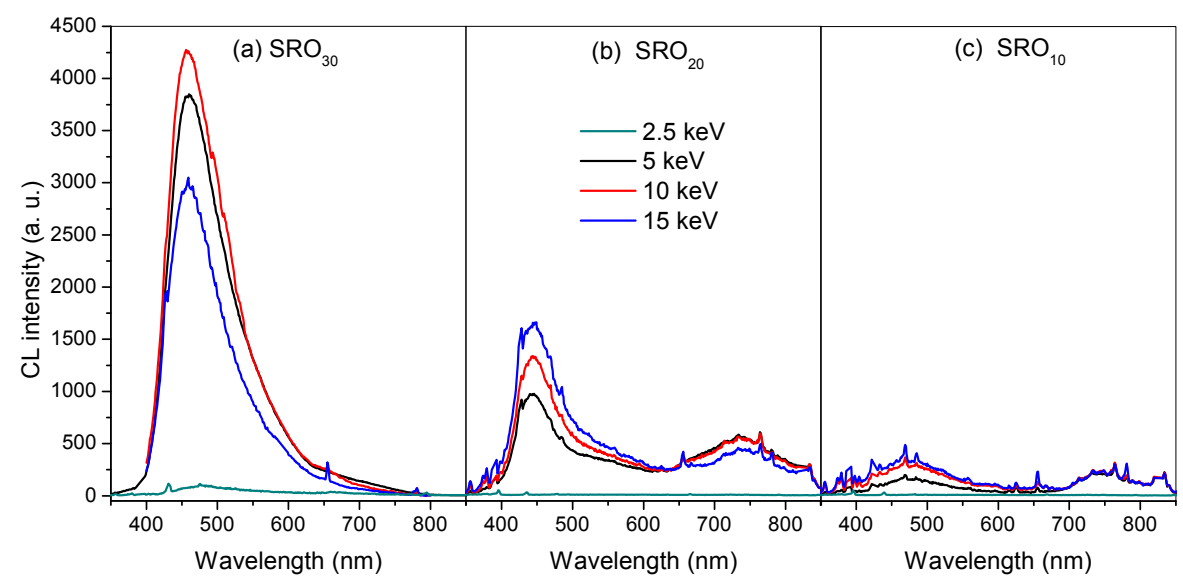

Fig. 11. Cathodoluminescence spectra of SRO annealed films at various electron energies. The spectra were measured at the room temperature. 


\subsection{Effect of the electron excitation on the emissive centers}

In order to study the effect of the cathode excitation on the emissive centers, PL spectra were obtained before and after CL measurements with different energy electron doses; additionally, the effect of time excitation on CL spectra was obtained.

Different $\mathrm{SRO}_{20}$ and $\mathrm{SRO}_{30}$ annealed samples at $1100^{\circ} \mathrm{C}$ in $\mathrm{N}_{2}$ by 180 minutes were used. One sample was not cathode-excitated, and it was used as reference. CL measurements were performed applying energy of 2.5, 5, 10 and $15 \mathrm{keV}$ in each sample, respectively. In all cases the current used in the experiment was fixed at $0.3 \mathrm{~mA}$.
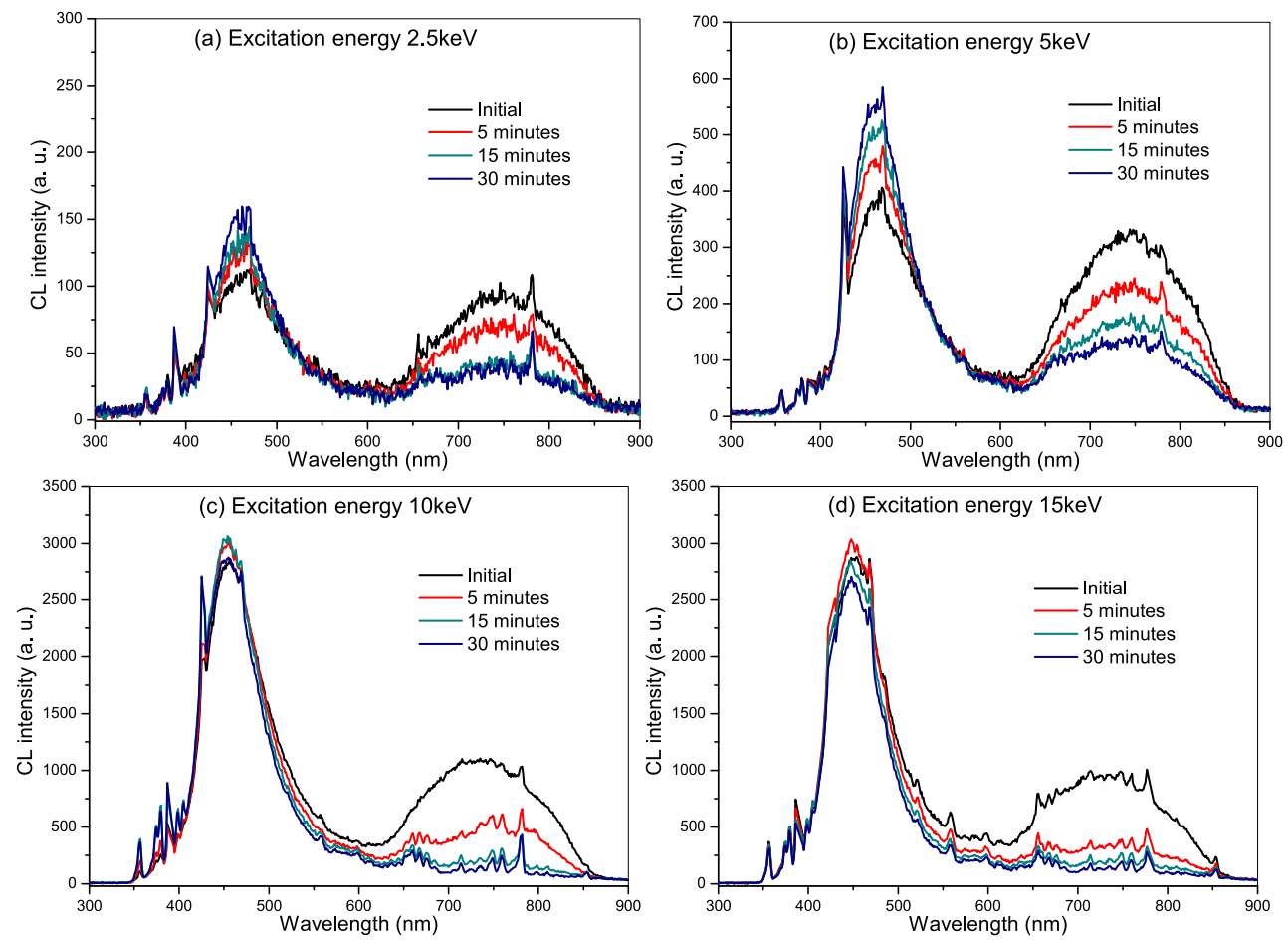

Fig. 12. CL spectra of $\mathrm{SRO}_{20}$ after different times of electron bombardment. Different samples were used: (a) sample excited with $2.5 \mathrm{keV}$, (b) sample excited with $5 \mathrm{keV}$, (c) sample excited with $10 \mathrm{keV}$, (d) sample excited with $15 \mathrm{keV}$.

CL spectra of $\mathrm{SRO}_{20}$ samples after different times of electron bombardment and different energy are shown in Fig. 12. CL spectrum consists of a broad emission in the visible and near infrared region (NIR) from $\sim 400$ to $850 \mathrm{~nm}$. The different excitation energies produce both characteristic bands of $\mathrm{SRO}_{20}$ (red and blue). It can be observe in all the samples and independent of excitation energy that the blue emission does not have a considerable change while red band rapidly decrease or quenched with cathodo-excitation time. Therefore the excitation with high energy electrons destroys or modifies the red emissive states, inclusive with low energy $(2.5 \mathrm{keV})$. Using electron energies greater than or equal to $10 \mathrm{keV}$, red band practically disappears after 5 minutes of bombardment. 
PL spectra obtained after constant electron beam excitation during 30 minutes continually are shown in Fig. 13. After apply excitation energy of 2.5, 5 and $10 \mathrm{keV}$, the PL emission decreases considerately (50\%), and with $15 \mathrm{keV}$ PL emission is reduced $80 \%$. This indicates that electron beam excitation modifies the structure of SRO due to the high energies used, and emission mechanism or emission centers were destroyed. Also it can be observed that after high energy excitation there is no new emission band.

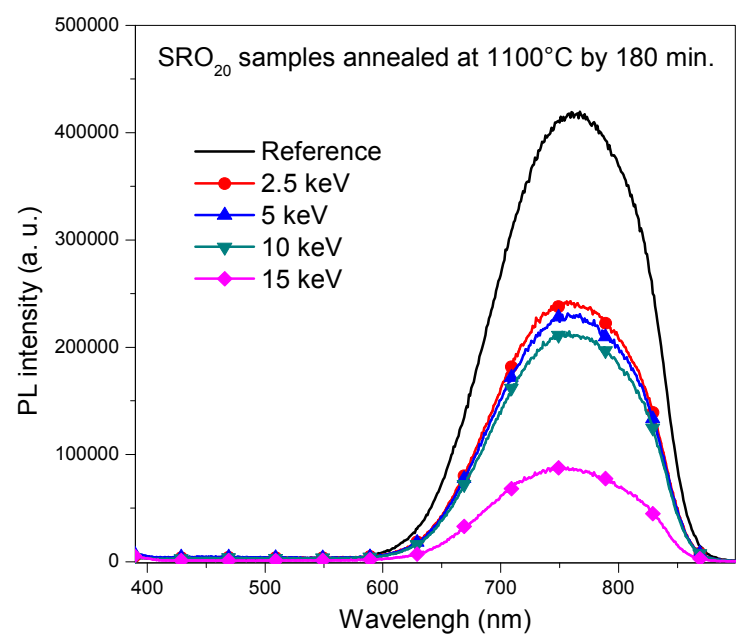

Fig. 13. PL spectra of $\mathrm{SRO}_{20}$ samples after continuous cathode-excitation during 30 minutes. Solid line is the reference sample emission (without electron beam irradiation). The symbols represent the PL emission after cathodo excitation.

The evolution of CL spectra for $\mathrm{SRO}_{30}$ annealed samples after 10minutes of constant electron bombardment is shown in Fig. 14 (a), (b) and (c) with 5, 10 and $15 \mathrm{keV}$ respectively. There is no CL emission when these samples were excited with $2.5 \mathrm{keV}$. Samples excited with higher energies (more than $5 \mathrm{keV}$ ) exhibit strong blue emission with a shoulder in higher wavelength, characteristic emission of $\mathrm{SRO}_{30}$. Blue emission centered at $\sim 460 \mathrm{~nm}$ increases after 10 minutes of constant cathode excitation. The PL spectra of these samples were obtained after constant electron beam excitation during 10 minutes, and shown in Fig. 15. Similar to $\mathrm{SRO}_{20}$, after cathode-excitation the PL emission decreases considerately $(\sim 50 \%)$, and as energy electron increase the PL emission reduces.

As mentioned before, blue emission centered at $\sim 460 \mathrm{~nm}$ has been assigned to oxygen deficiency. Also, it has been proposed that high energy excitation and long exposition time are responsible of this band in $\mathrm{SiO}_{2}$ (Chen et al., 1999; Goldberg et al., 1997; Inokuma et al., 1998). Since blue emission increases slightly after constant electron excitation in SRO, it is possible that oxygen deficiencies are created by excitation. However, we can assume that the emission in the blue region is due to the non-stoichiometry of the SRO because blue emission is not observed in PL neither before nor after of cathode excitation. Besides, blue emission has also been found in thermoluminescence and electroluminescence in SRO deposited by LPCVD (Morales-Sánchez et al., 2010; Piters et al., 2010). Therefore, the emission is due to band to band recombination through localized states in the SRO. 
Degradation of the intensity in red region could be due to the passivation of luminescent centers. It is possible that the electron beam introduces changes around the emission center that affect the emission rate of emission of radiative and non radiative transitions.
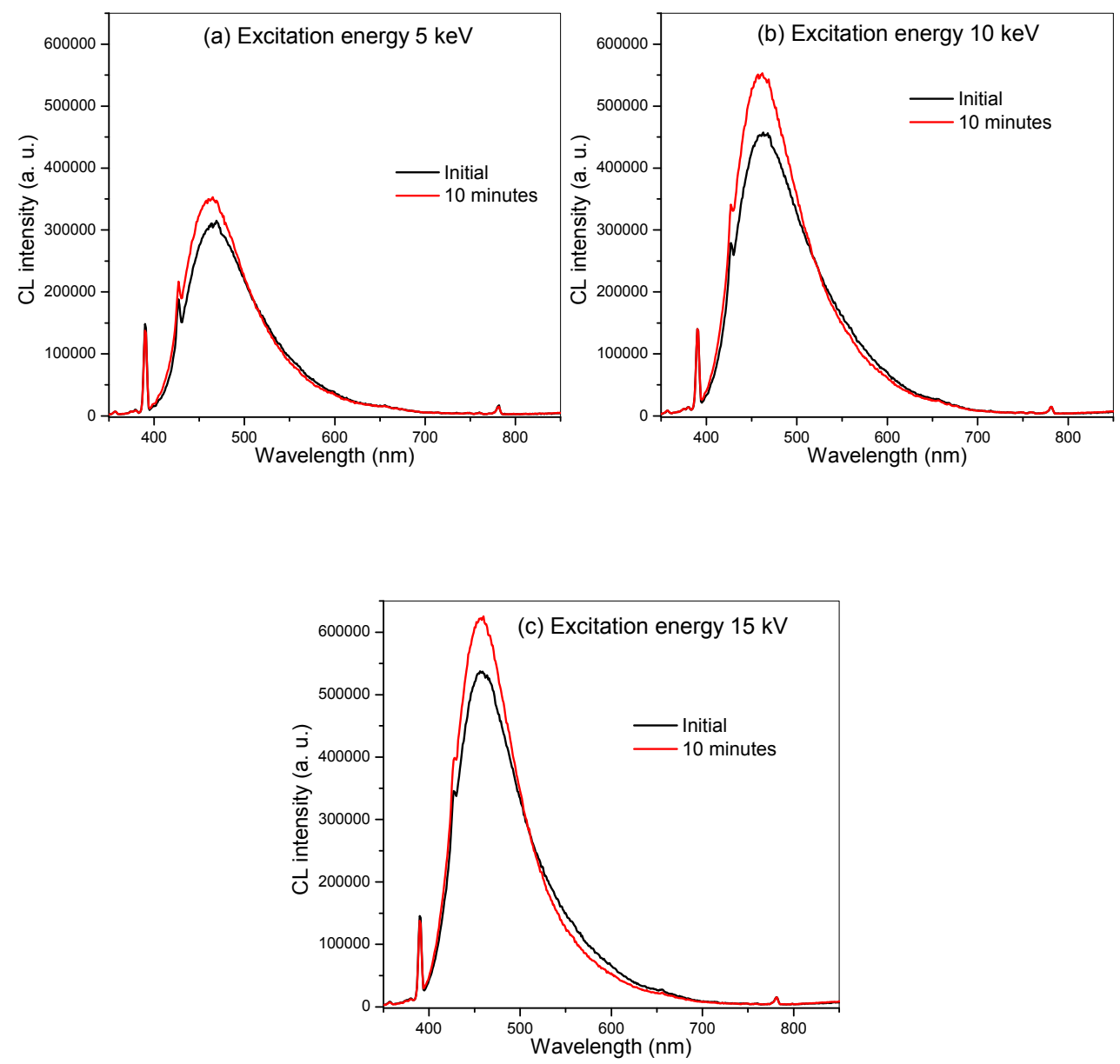

Fig. 14. CL spectra of $\mathrm{SRO}_{30}$ annealed samples after different times of electron bombardment. Different samples were used: (a) sample excited with $5 \mathrm{keV}$, (b) sample excited with $10 \mathrm{keV}$, (c) sample excited with $15 \mathrm{keV}$. 


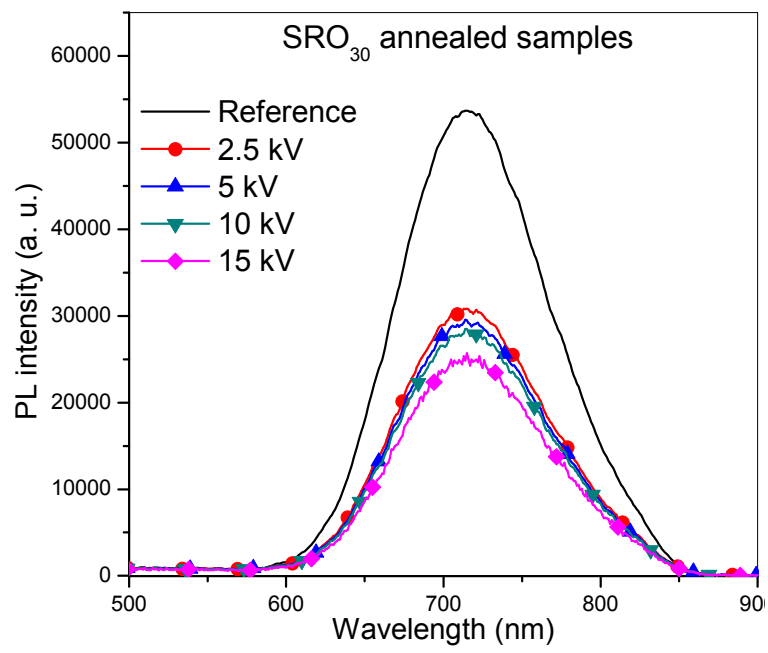

Fig. 15. PL spectra of $\mathrm{SRO}_{30}$ after cathode excitation at different beam energies. A sample without electron beam irradiation was used as reference (solid line).

\section{Conclusion}

SRO films with different silicon excess and with and without thermal treatment were studied using CL and PL. In order to understand their emission FTIR and XPS were used to study the structural composition and the effect of thermal treatment. FTIR and XPS results show the formation of si nanoaglomerates in all samples. Analysis of the XPS Si $2 p$ peaks shows the existence of some chemical structures corresponding to the Si oxidation states in the SRO films; these oxidation states depend on the silicon excess. The concentration of each oxidation state was estimated. According to variation of silicon compounds found in analysis of the Si $2 p$ spectra, we can assume that as silicon excess decrease Si-nCs density decreases and defects (or silicon oxygen compounds) tend to predominate over Si nanoclusters or nanocrystals. In fact, when the Si nanoclusters are very small, the interface will play important role due to the large stress in the interface of the nanoclusters and the localized states will be form.

Photo and Cathodoluminescence (PL and CL) properties in Silicon Rich Oxide (SRO) films with different silicon excess were studied. SRO deposited by LPCVD has shown high visible PL and CL emission at room temperature mainly after thermal treatment at high temperatures. Samples with lower silicon excess show maximum luminescence while samples with higher silicon excess show low luminescence. Strong emission from 650 to 800 $\mathrm{nm}$ was found in PL while CL spectra show luminescence emission from 400 to $850 \mathrm{~nm}$ in SRO annealed samples. CL spectra are wider than the PL one, because high energy excitation leads the emission of all the emissive centers present in the SRO. Also was found that red and NIR region emission is affected by electron beam.

Luminescent emission in blue-green region is mainly due to defect created by silicon excess, such as oxygen deficiency-related centers (ODC), $E^{\prime} \delta$ defect, and non-bridging oxygen hole centers (NBOHC). Emission in red and near infrared region is associated to some defects that are acting as localized states and also to $\mathrm{Si}$ nanoaglomerates and defects interaction. 


\section{Acknowledgment}

The authors express their thanks to the microelectronic laboratory technicians of INAOE for their support and to the CONACYT for providing financial support for this work.

\section{References}

Aceves, M., Falcony, C., Reynoso-Hernandez, A., C. W., \& Torres, A. (1996). The conduction properties of the silicon/off-stoichiometry-SiO 2 diode. Solid-State Electronics, Vol. 39 No. 5, (May 1996 ), pp. 637-644, ISSN 00381101.

Aceves, M., Malik, A., \& Murphy, R. (2001). The FTO/SRO/SI structure as a radiation sensor, In: Sensors \& Chemometrics, M. T. Ramírez-Silva, M. A. Romero Romo, \& M. E. Palomar Pardavé (Ed.), 1-25, Research Signpost, ISBN 81-7736-067-1, India.

Aceves, M., Pedraza, J., Reynoso-Hernandez, J. A., Falcony, C., \& Calleja, W. (1999). Study on the $\mathrm{Al} /$ silicon rich oxide/Si structure as a surge suppressor, DC, frequency response and modeling. Microelectronics Journal,Vol. 30, No. 9, (September 1999), pp. 855-862, ISSN 00262692.

Alfonsetti, R., Lozzi, L., Passacantando, M., Picozzi, P., \& Santucci, S. (1993). XPS studies on SiOx thin films. Applied Surface Science, Vol. 70-71, No. part 1,(June 1993), pp. 222225, ISSN 01694332.

Ay, F., \& Aydinli, A. (2004). Comparative investigation of hydrogen bonding in silicon based PECVD grown dielectrics for optical waveguides. Optical Materials, Vol. 26 No. 1, (June 2004), pp. 33-46, ISSN 09253467.

Brüesch, P., Stockmeier, T., Stucki, F., \& Buffat, P. A. (1993). Physical properties of semiinsulating polycrystalline silicon. I. structure, electronic properties, and electrical conductivity. Journal of Applied Physics, Vol. 73, No. 11, (n. d.), pp. 7677-7689, ISSN 00218979.

Calleja, W., Aceves, M., \& Falcony, C. (1998). EEPROM transistor fabricated with stacked SiOx LPCVD films. Electronics Letters, Vol. 34, No. 13, (June 1998), pp. 1294-1296, ISSN 00135194.

Cervera, M., Hernández, M. J., Rodríguez, P., Piqueras, J., Avella, M., González, M. A., \& Jimenez, J. (2006). Blue-cathodoluminescent layers synthesis by high-dose $\mathrm{N}^{+}, \mathrm{C}^{+}$ and $\mathrm{B}^{+} \mathrm{SiO}_{2}$ implantation. Journal of Luminescence, Vol. 117, No.1, (March 2006), pp. 95-100, ISSN 00222313.

Chen, C. M., Pan, H. C., Zhu, D. Z., Hu, J., \& Li, M. Q. (1999). Cathodoluminescence and ion beam analysis of ion-implanted combinatorial materials libraries on thermally grown $\mathrm{SiO}_{2}$. Nuclear Instruments and Methods in Physics Research. Vol. 159 No.1-2, pp. 81-88, ISSN 0168583X.

Chen, X. Y., Lu, Y. F., Tang, L. J., Wu, Y. H., Cho, B. J., Xu, X. J., Dong, J. R \& Song, W. D. (2005). Annealing and oxidation of silicon oxide films prepared by plasmaenhanced chemical vapor deposition. Journal of Applied Physics, Vol. 97 No. 1, (January 2005), pp. 014913-1-014913-1, ISSN 00218979.

Chen, X. Y., Lu, Y. F., Wu, Y. H., Cho, B. J., Song, W. D., \& Dai, D. Y. (2004). Optical properties of $\mathrm{SiOx}$ nanostructured films by pulsed-laser deposition at different substrate temperatures. Journal of Applied Physics, Vol. 96, No. 6, (September 2004), pp. 3180-3186, ISSN 00218979. 
Chen, X. Y., Lu, Y. F., Wu, Y. H., Cho, B. J., Tang, L. J., Lu, D., \& Dong, J. R. (2006). Correlation between optical properties and si nanocrystal formation of si-rich si oxide films prepared by plasma-enhanced chemical vapor deposition. Applied Surface Science, Vol. 253, No. 5, (December 2006), pp. 2718-2726, ISSN 01694332.

Daldosso, N., Das, G., Larcheri, S., Mariotto, G., Dalba, G., Pavesi, L., Irrera, A., Priolo, F., Iacona, F. \& Rocca, F. (2007). Silicon nanocrystal formation in annealed silicon-rich silicon oxide films prepared by plasma enhanced chemical vapor deposition. Journal of Applied Physics, Vol. 101, No. 11, (n. d.), ISSN 00218979.

Dehan, E., Temple-Boyer, P., Henda, R., Pedroviejo, J. J., \& Scheid, E. (1995). Optical and structural properties of SiOx and SiNx materials. Thin Solid Films, Vol. 266, No. 1, (September 1995), pp. 14-19, ISSN 00406090.

DiMaria, D. J., Kirtley, J. R., Pakulis, E. J., Dong, D. W., Kuan, T. S., Pesavento, F. L., Theis, T., \& Cutro, J. A. (1984). Electroluminescence studies in silicon dioxide films containing tiny silicon islands. Journal of Applied Physics, Vol. 56, No. 2, pp. 401-416, ISSN 00218979.

Dong, D., Irene, E. A., \& Young, D. R. (1978). Preparation and some properties of chemically vapor-deposited Si-rich $\mathrm{SiO}_{2}$ and $\mathrm{Si}_{3} \mathrm{~N}_{4}$ films. Journal of the Electrochemical Society, Vol. 125, No. 5, (May 1978), pp. 819-823, ISSN 00134651.

Fazio, E., Barletta, E., Barreca, F., Neri, F., \& Trusso, S. (2005). Investigation of a nanocrystalline silicon phase embedded in SiOx thin films grown by pulsed laser deposition. Journal of Vacuum Science and Technology B, Vol. 23, No. 2, (n. d.), pp. 519-524, ISSN 10711023.

Fitting, H. J. (2009). Can we make silica luminescent?. Optical Materials, Vol. 31, No. 12, (October 2009), pp. 1891-1893, ISSN 09253467.

Fitting, H. J., Barfels, T., \& Trukhin, A. N. (2001). Cathodoluminescence of crystalline and amorphous $\mathrm{SiO}_{2}$ and $\mathrm{GeO}_{2}$. Journal of Non-Crystalline Solids, Vol. 279, No. 1, (January 2001), pp. 51-59, ISSN 00223093.

Goldberg, M., Barfels, T., \& Fitting, H. J. (1998). Cathodoluminescence depth analysis in $\mathrm{SiO}_{2}$-Si-systems. Fresenius' Journal of Analytical Chemistry, Vol. 361 No. 6-7, (n. d.), pp. 560-561, ISSN 09370633.

Goldberg, M., Fitting, H. J., \& Trukhin, A. (1997). Cathodoluminescence and cathodoelectroluminescence of amorphous $\mathrm{SiO}_{2}$ films. Journal of Non-Crystalline Solids, Vol. 220, No. 1, (October 1997), pp. 69-77, ISSN 00223093.

Gritsenko, V. A., Shavalgin, Y. G., Pundur, P. A., Wong, H., \& Lau, W. M. (1999). Cathodoluminescence and photoluminescence of amorphous silicon oxynitride. Microelectronics Reliability, Vol. 39, No. 5, (May 1999), pp. 715-718, ISSN 00262714.

Hanaizumi, O., Ono, K., \& Ogawa, Y. (2003). Blue-light emission from sputtered $\mathrm{Si}^{\mathrm{SiO}_{2}}$ films without annealing. Applied Physics Letter, Vol. 82, No. 4, (January 2003), pp. 538-540, ISSN 00036951.

Iacona, F., Franzo, G., \& Spinella, C. (2000). Correlation between luminescence and structural properties of Si nanocrystals. Journal of Applied Physics, Vol. 87, No. 3, (February 2000), pp. 1295-1303, ISSN 00218979.

Inokuma, T., Kurata, Y., \& Hasegawa, S. (1998). Cathodoluminescence properties of silicon nanocrystallites embedded in silicon oxide thin films. Journal of Luminescence, Vol. 80, No. 1-4, (December 1998), pp. 247-251, ISSN 00222313. 
Irene, E. A., Chou, N. J., Dong, D. W., \& Tierney, E. (1980). On the Nature of CVD Si-Rich $\mathrm{SiO}_{2}$ and $\mathrm{Si}_{3} \mathrm{~N}_{4}$ Films. J. Electrochem. Soc., Vol. 127, No. 11, pp. 2518-2521.

Kenyon, A. J., Trwoga, P. F., Pitt, C. W., \& Rehm, G. (1996). The origin of photoluminescence from thin films of silicon-rich silica. Journal of Applied Physics, Vol. 79, No. 12, (June 1996), pp. 9291-9300, ISSN 00218979.

Khriachtchev, L., Novikov, S., \& Lahtinen, J. (2002). Thermal annealing of $\mathrm{Si} / \mathrm{SiO}_{2}$ materials: Modification of structural and photoluminescence emission properties. Journal of Applied Physics, Vol. 92, No. 10, (November 2002), pp. 5856-5862, ISSN 00218979.

Liu, Y., Chen, T. P., Fu, Y. Q., Tse, M. S., Hsieh, J. H., Ho, P. F., \& Liu Y. C. (2003). A study on si nanocrystal formation in Si-implanted $\mathrm{SiO}_{2}$ films by x-ray photoelectron spectroscopy. Journal of Physics D, Vol. 36, No. 19, (October 2003), pp. L97-L100, ISSN 00223727.

Lockwood, D. J., Lu, Z. H., \& Baribeau, J. (1996). Quantum confined luminescence in $\mathrm{Si} / \mathrm{SiO}_{2}$ superlattices. Physical Review Letters, Vol. 76, No. 3, (n. d.), pp. 539-541, ISSN 00319007.

López-Estopier, R., Aceves-Mijares, M., Yu, Z., \& Falcony, C. (2011). Determination of the energy states of the donor acceptor decay emission in silicon rich oxide prepared by low-pressure chemical vapor deposition. Journal of Vacuum Science and Technology B: Microelectronics and Nanometer Structures, Vol. 29, No. 2, (March 2011), ISSN 10711023.

Morales, A., Barreto, J., Domínguez, C., Riera, M., Aceves, M., \& Carrillo, J. (2007). Comparative study between silicon-rich oxide films obtained by LPCVD and PECVD. Physica E: Low-Dimensional Systems and Nanostructures, Vol. 38, No. 1-2, (April 2007), pp. 54-58, ISSN 13869477.

Morales-Sánchez, A., Aceves-Mijares, M., González-Fernández, A. A., Monfil-Leyva, K., Juvert, J., \& Domínguez-Horna, C. (2010). Blue and red electroluminescence of silicon-rich oxide light emitting capacitors. Proceedings of SPIE - the International Society for Optical Engineering, Vol. 7719, ISBN 978-081948192-4, Brussels, Belgium, April 12, 2010.

Morales-Sánchez, A., Barreto, J., Domínguez-Horna, C., Aceves-Mijares, M., \& Luna-López, J. A. (2008). Optical characterization of silicon rich oxide films. Sensors and Actuators, A: Physical, Vol. 142, No. 1, (March 2008), pp. 12-18, ISSN 09244247.

Nesbit, L. A. (1985). Annealing characteristics of si-rich $\mathrm{SiO}_{2}$ films. Applied Physics Letters, Vol. 46, No. 1, (n. d.), pp. 38-40, ISSN 00036951.

Pai, P. G., Chao, S. S., Takagi, Y., \& Lucovsky, G. (1986). Infrared spectroscopic study of $\mathrm{SiOx}$ films produced by plasma enhanced chemical vapor deposition. Journal of Vacuum Science E Technology A: Vacuum, Surfaces, and Films, Vol. 4, No. 3, pp. 689694.

Pavesi, L., Dal Negro, L., Mazzoleni, C., \& Franzo, G. (2000). Optical gain in silicon nanocrystals. Nature, Vol. 408, No. 6811, (November 2000), pp. 440-444, ISSN 00280836.

Philipp, H. R. (1972). Optical and bonding model for non-crystalline SiOx and SiOxNy materials. Journal of Non-Crystalline Solids, Vol. 8-10, No.C, (June 1972), pp. 627-632, ISSN 00223093. 
Piters, T., Aceves-Mijares, M., D., B. M., Berriel-Valdos, L., \& Luna-López, J. A. (2010). Dose dependent shift of the TL glow peak in a silicon rich oxide (SRO) film. Revista mexicana de fisica, Vol. S 57, No. 2, pp. 26-29.

Ribeiro, M., Pereyra, I., \& Alayo, M. (2003). Silicon rich silicon oxynitride films for photoluminescence applications. Thin Solid Films, Vol. 426, No. 1-2, (February 2003), pp. 200-204, ISSN 00406090.

Shimizu-Iwayama, T., Yoichi, T., Atsushi, K., Motonori, K., Setsuo, N., \& Kasuo, N. (1996). Visible photoluminiscence from nanocrystal formed in silicon dioxide by ion implantation and thermal processing. Thin Solid Films, Vol. 276, No. 1-2, (April 1996), pp. 104-107, ISSN 00406090.

Trukhin, A. N., Fitting, H. J., Barfels, T., \& Czarnowski, V. (1999). Cathodoluminescence and IR absorption of oxygen deficient silica - influence of hydrogen treatment. Journal of Non-Crystalline Solids, Vol. 260, No. 1-2, (December 1999), pp. 132-140, ISSN 00223093.

Wang, Y. Q., Chen, W. D., Liao, X. B., \& Cao, Z. X. (2003). Amorphous silicon nanoparticles in compound films grown on cold substrates for high-efficiency photoluminescence. Nanotechnology, Vol. 14, No. 11, (November 2003), pp. 12351238, ISSN 09574484.

Wittry, D. B., \& Kyser, D. F. (1967). Measurement of diffusion lengths in direct-gap semiconductors by electron-beam excitation. Journal of Applied Physics, Vol. 38, No. 1, (n. d.), pp. 375-382, ISSN 00218979.

Yacobi, B. G., \& Holt, D. B. (1990). Cathodoluminescence Microscopy of inorganic solids, Springer, ISBN 0-306-43314-1, New York:, USA.

Yang, D. Q., Gillet, J. N., Meunier, M., \& Sacher, E. (2005). Room temperature oxidation kinetics of si nanoparticles in air, determined by x-ray photoelectron spectroscopy. Journal of Applied Physics, Vol. 97, No. 2, (January 2005), pp. 024303-1-024303-6, ISSN 00218979.

Yu, Z., Aceves, M., Carrillo, J., \& Flores, F. (2003). Single electron charging in si nanocrystals embedded in silicon-rich oxide. Nanotechnology, Vol. 14, No. 9, (September 2003), pp. 959-964, ISSN 09574484.

Yu, Z., Aceves-Mijares, M., Luna-López, A., Du, J., \& Bian, D. (2006b). Formation of silicon nanoislands on crystalline silicon substrates by thermal annealing of silicon rich oxide deposited by low pressure chemical vapour deposition. Nanotechnology, Vol. 17, No. 1, (October 2006), pp. 4962-4965, ISSN 09574484.

Yu, Z., Mariano, A., Luna-López, A., Quiroga, E., \& López-Estopier, R. (2006a). Photoluminescence and single electron effect of nanosized silicon materials, In Focus on Nanomaterials Research, B. M. Caruta (Ed.), pp. 233-273, Nova Science Publishers, ISBN 1-59454-897-8, New York, USA. 


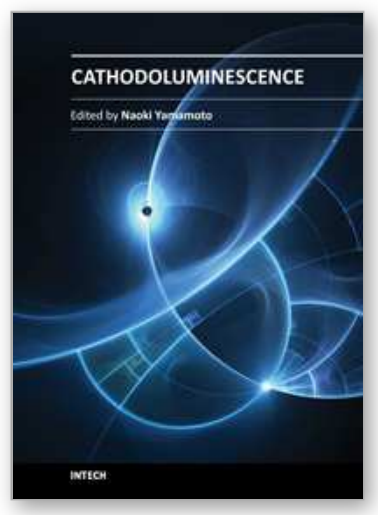

\author{
Cathodoluminescence \\ Edited by Dr. Naoki Yamamoto
}

ISBN 978-953-51-0362-2

Hard cover, 324 pages

Publisher InTech

Published online 28, March, 2012

Published in print edition March, 2012

Cathodoluminescence $(\mathrm{CL})$ is a non-destructive technique to characterize optical and electronic properties of nanostructures in many kinds of materials. Major subject is to investigate basic parameters in semiconductors, impurities in oxides and phase determination of minerals. CL gives information on carrier concentration, diffusion length and life time of minority carriers in semiconductors, and impurity concentration and phase composition in composite materials. This book involves 13 chapters to present the basics in the $\mathrm{CL}$ technique and applications to particles, thin films and nanostructures in semiconductors, oxides and minerals. The chapters covered in this book include recent development of $C L$ technique and applications to wide range of materials used in modern material science.

\title{
How to reference
}

In order to correctly reference this scholarly work, feel free to copy and paste the following:

Rosa López-Estopier, Mariano Aceves-Mijares and Ciro Falcony (2012). Cathodo- and Photo- Luminescence of Silicon Rich Oxide Films Obtained by LPCVD, Cathodoluminescence, Dr. Naoki Yamamoto (Ed.), ISBN: 978953-51-0362-2, InTech, Available from: http://www.intechopen.com/books/cathodoluminescence/cathodo-andphoto-luminescence-of-silicon-rich-oxide-films-obtained-by-Ipcvd

\section{INTECH}

open science | open minds

\section{InTech Europe}

University Campus STeP Ri

Slavka Krautzeka 83/A

51000 Rijeka, Croatia

Phone: +385 (51) 770447

Fax: +385 (51) 686166

www.intechopen.com

\section{InTech China}

Unit 405, Office Block, Hotel Equatorial Shanghai

No.65, Yan An Road (West), Shanghai, 200040, China 中国上海市延安西路65号上海国际贵都大饭店办公楼 405 单元

Phone: +86-21-62489820

Fax: $+86-21-62489821$ 
(C) 2012 The Author(s). Licensee IntechOpen. This is an open access article distributed under the terms of the Creative Commons Attribution 3.0 License, which permits unrestricted use, distribution, and reproduction in any medium, provided the original work is properly cited. 